\title{
Role of innate lymphoid cells in allergic diseases
}

\author{
M. Asghar Pasha, M.D., ${ }^{1}$ Gargi Patel, M.D., ${ }^{1}$ Russell Hopp, D.O., ${ }^{2}$ and Qi Yang, M.D., Ph.D. ${ }^{3}$
}

\begin{abstract}
Background: Over the past decade, there has been increasing interest and research into understanding the type 2 immune responses by the epithelium-derived cytokines interleukin (IL) 33, IL-25, and thymic stromal lymphopoietin. Innate lymphoid cells (ILC) are a unique family of effector immune cells that functionally resemble $T$ cells but lack clonal distributed antigen receptors. Group 2 ILCs, ILC2s, are known for their capability to secrete proallergic cytokines, including IL-5 and IL-13. ILC2s are enriched at mucosal barriers in lung, gut, and skin, and their activation has been associated with a variety of allergic disorders.

Objective: To study the role of ILC2 in different allergic disorders, including allergic rhinitis, asthma, atopic dermatitis, and food allergies.

Methods: A MEDLINE search was performed for articles that reported on ILC2 in allergic disorders, including allergic rhinitis, asthma, atopic dermatitis, and food allergies.

Results: A review of the literature revealed an important role of ILC2 in various allergic disorders.

Conclusion: Identification of ILC2s in patients with allergic rhinitis, asthma, and atopic dermatitis indicates that these cells may represent a new therapeutic target. In this review, we discussed the current understanding of ILC2 biology and its function and regulation in various allergic diseases.
\end{abstract}

(Allergy Asthma Proc 40:138-145, 2019; doi: 10.2500/aap.2019.40.4217)

$\mathbf{T}$ he discovery of the innate lymphoid cell (ILC) family has greatly expanded our knowledge within the past 8 years. ILCs are unique subsets of lymphocytes that do not express rearranged antigen receptors but transcriptionally and functionally mirror T-helper (Th) cells. ILCs have been categorized into three different groups, viz., ILC1, ILC2, and ILC3, based on their distinct pattern of cytokine production and transcription factors. ILC2s are described in both humans and mice, and can induce a type 2 inflammatory response. ${ }^{1}$ ILC2s share many functional similarities with Th2 lymphocytes because they produce type 2 cytokines interleukin (IL) 4, IL-5, IL-9, and IL-13 as well as other effector molecules, e.g., vascular endothelial growth factor (VEGF). ${ }^{2-10} \mathrm{~A}$ subset of IL-25-responsive ILC2s, in addition, produce IL-17 and is termed inflammatory ILC2. ${ }^{11}$

Unlike T cells that recognize specific antigens, ILC2s respond to nonspecific cell-derived factors, such as IL-33, IL-25, and thymic stromal lymphopoietin (TSLP), and to eicosanoids. ${ }^{2-5,12-15}$ Both human and

\footnotetext{
From the ${ }^{1}$ Division of Allergy and Immunology, Albany Medical College, Albany, New York, ${ }^{2}$ Division of Allergy and Immunology, Creighton University, Omaha, Nebraska, and ${ }^{3}$ Department of Immunology and Microbial Diseases, Albany Medical College, Albany, New York

This work is supported by NIH grant 1R01HL137813.

The authors have no conflicts of interest to declare pertaining to this article

Address correspondence to M. Asghar Pasha, M.D., Division of Allergy and Immunology, Albany Medical College, 176 Washington Avenue Extension, Suite 102, Albany, NY 12203

E-mail address: pasham@amc.edu

Copyright (C) 2019, OceanSide Publications, Inc., U.S.A.
}

mouse ILC2 produce large amounts of IL-5 and IL-13, which promote airway inflammation and hyperresponsiveness. An interesting difference has been observed between mouse and human ILC2 with regard to IL-4 production. Activated mouse ILC2s do not readily secrete IL-4 in response to IL-25 and IL-33, although they may be induced to produce IL-4 by leukotriene D4. However, activated human ILC2 produce large amounts of IL-4, which indicates that human ILC2 might be involved in Th2 priming. ${ }^{3,13,16}$ ILC2 numbers are increased in the tissues of patients with various allergic disorders, including allergic rhinitis (AR), asthma, atopic dermatitis (AD), and eosinophilic esophagitis (EoE). ${ }^{14,17-20}$ In this review, we summarized the current understanding about the function and regulation of ILCs in various allergic diseases.

\section{ALLERGIC RHINITIS}

Classic symptoms of AR include sneezing, rhinorrhea, nasal pruritus, and congestion, caused by an immunoglobulin E (IgE) mediated an early phase response due to allergen exposure. ${ }^{21,22}$ A number of studies showed evidence of increased epithelial proinflammatory cytokines in patients with AR. IL-25, IL-33, and TSLP were detected in the nasal lavage from patients with house-dust mite (HDM) sensitivity. ${ }^{23,24}$ Furthermore, IL-33 and TSLP messenger RNA (mRNA) levels were high in nasal epithelium of patients with $\mathrm{AR}^{25-29} \mathrm{IL}-33$ is thought to cause both IgE-mediated histamine release as well as release of IgE-independent cytokines and chemokines from mast cells. ${ }^{25}$ Wang et $a l^{30}$ showed that allergen stimulation of basophils 
from patients allergic to grass or birch pollen upregulated IL-25 expression in peripheral blood mononuclear cells (PBMC) compared with controls. Moreover, high levels of IL-25R mRNA expression by $\mathrm{CD}^{+}$cells in PBMCs from patients with AR were reported. ${ }^{30,31}$ This study also demonstrated that cellular apoptosis was inhibited by IL-25 stimulation of basophils and enhanced IgE-mediated degranulation. ${ }^{30}$

There is emerging evidence that proallergic cytokines and ILC2 pathways contribute to the pathogenesis of inflammatory nasal diseases, particularly AR. There is some evidence that the number of ILC2s correlates with the severity of nasal disease, which may have clinical implication in the management of AR, especially in patients resistant to treatment. ${ }^{32}$ Doherty et al. ${ }^{33}$ demonstrated that the percentage of prostaglandin D2 receptor 2 (CRTH2)-expressing ILC2 is increased in peripheral blood after allergen challenge in patients with cat allergy. Similarly, Zhong et al. ${ }^{34} \mathrm{dem}-$ onstrated that ILC2 levels were elevated in patients with HDM sensitivity and the level of peripheral blood ILC2 correlated with symptom severity. Interestingly, Fan et al. ${ }^{35}$ found that the level of ILC2 was elevated in the peripheral blood of patients with AR and with HDM sensitivity compared with healthy controls; however, there was no difference between the ILC2 levels in patients with AR with mugwort sensitivity compared with healthy controls. A possible explanation given by the investigators is that HDM stimulates a stronger immune response to ILC2 than do plant allergens, e.g., mugwort, or a different pathway is used to stimulate an immune response by HDM allergens than by plant allergens. They further showed that there was a significantly greater release of IL-13 and IL-5 from PBMC when incubated with IL-33 with or without IL-25 in the presence of IL-2 in patients with AR and with HDM sensitivity compared with mugwort sensitivity, which suggests that ILC2 plays a role in AR secondary to HDM sensitivity by producing IL-5 and IL-13. ${ }^{35}$

Allergen immunotherapy (AIT), treatment for allergic rhinitis, has been an area of interest to find markers for therapeutic success. Studies in patients responsive to AIT, showed a decreased response from ILC2 with allergen stimulation than healthy controls. ${ }^{36}$ Other experiments done by this same group also looked at the role of ILC1 and ILC3 along with ILC2 in AR. Furthermore, the ILC2:ILC1 ratio in patients who responded to AIT was similar to those of healthy controls, which suggested a possible role of ILCs as a biomarker for therapeutic response with AIT in patients with AR. Lombardi et al., ${ }^{37}$ found that ILC2 and ILC3 frequencies were significantly increased in grass-allergic patients during the grass pollen season only whereas the frequency of ILC1 did not vary. Furthermore, they showed that sublingual immunotherapy in patients outside of the pollen season did not significantly affect ILC1, ILC2, and ILC3. ILC1 from patients with AR produced less interferon gamma (IFN $\gamma$ ) compared with patients without $\mathrm{AR}$ with an in vitro stimulation. Whole-transcriptome analysis showed upregulation of murine osteosarcoma viral oncogene homolog (FOS), murine osteosarcoma viral oncogene homolog B (FOSB), and Jun Activation Domain Binding Protein (JUN) genes in ILC2 from patients with AR compared with patients without AR. This indicated that, not only is regulation of ILC2 complex and multifactorial, but there is evidence to indicate differences in regulation of ILC1 and ILC3 between patients with AR and compared with healthy controls. ${ }^{37}$

Kato et al. ${ }^{38}$ developed a novel mouse model to study localized allergic rhinitis in which they nasally sensitized mice to ragweed. In this murine model, they found ILC2 in the nasal mucosa. They further studied innate immunity in these nasally sensitized mice by using $\mathrm{T}$ - and $\mathrm{B}$-cell deficient recombinant activation gene 2 (Rag2) ${ }^{-1-}$ mice. ${ }^{38}$ They found that, although there was reduced infiltration of eosinophils at an early time point, there still was some influx of eosinophils compared with a phosphate buffered saline (PBS) control group, which indicated that ILC2 may have a role in early eosinophil infiltration; however, eosinophil infiltration was almost nonexistent at a later time point suggesting ILC2 do not have a role in late eosinophil infiltration in nasally sensitized $A \mathrm{AR}^{38}$ This data indicates that that $\mathrm{T}$ cells may be crucial for mast cell and/or basophil responses and that ILC2 alone may not induce strong localized inflammatory responses; however, ILC2 can induce Th2 inflammation without the acquired immune system. Overall these experiments highlight the role of both the innate immune system and the adaptive immune system in nasal inflammation and responses. Further studies are required to assess the role of ILC2 in non-AR. ${ }^{38}$

\section{ASTHMA}

Asthma is characterized by inflammation, airway hyperresponsiveness, and reversible airflow obstruction. ${ }^{39}$ It was previously thought that asthma involved mostly Th2 cells and eosinophils; however, recently, it was shown that asthma is more than a Th2 response and is a heterogeneous disorder with several distinct phenotypes. ${ }^{40}$ Allergic asthma is triggered by exposure to allergens in a individual who is sensitized, which causes eosinophilic airway inflammation. Nonallergic asthma is associated with exposure to environmental triggers, such as cigarette smoke, diesel particles, ozone, viral infections, exercise, stress, and obesity. ${ }^{40}$ This phenotype is often associated with neutrophilic airway inflammation and innate immunity independent of Th2 cells. ${ }^{41-44}$ 
Asthma is mediated by Th2 cells, which play a critical role in this disease by production of cytokines, such as IL-4, IL-5, and IL-13. In asthma, IL-4 is important for isotype switching, which leads to increased $\operatorname{IgE}$ production, whereas IL-5 is important for eosinophil growth and differentiation. IL-13 causes airway hyperreactivity, a hallmark of asthma, by affecting epithelial cells and airway smooth-muscle cells. Several studies show that ILC2s are associated with allergic asthma. ${ }^{1}$ The initial studies of ILC2s were performed in murine models. ${ }^{2,4-5}$ Subsequent studies indicated that ILC2 has an important role in human respiratory tract. Allakhverdi et al. ${ }^{45}$ reported that IL-13- and IL-5-producing cells with characteristics of ILC2 cells were present in sputum of patients with asthma compared with healthy controls. They also found that these cells exhibited TSLP and IL-33 receptors, which produced IL13, IL-5, and chemokines when stimulated by TSLP and IL-33. When specific allergen challenge was performed, the number of ILC2 increased.

In another study, Prefontaine et al. ${ }^{46}$ reported that, in patients with severe asthma, airway epithelial cells, and airway smooth-muscle cells might be the source of IL-33. Bartemes et al., ${ }^{17}$ in a prospective study, investigated whether an ILC2 response can be used as a biomarker of human disease. PBMCs from patients with asthma, patients with AR, and healthy control subjects were cultured in vitro with IL-25 or IL-33. They found that innate type 2 responses were increased in patients with asthma compared with patients with AR. Lombardi et al. ${ }^{37}$ reported greater expression of type-2 cytokines, associated transcription factor, and signaling transduction molecules in ILC2 was found in subjects with atopy and asthma. An increased ILC2 number can be detected in the airways of patients with severe asthma. ${ }^{47}$ Furthermore, a high number of IL-5+ and IL-13+ ILC2s has been reported in sputum of patients with severe asthma with persistent eosinophilic airway inflammation, despite treatment with oral corticosteroids. ${ }^{48}$

Chen et al. ${ }^{49}$ investigated the role of ILC2 in allergeninduced airway eosinophilic responses in subjects with atopy and asthma. They found a significant increase in total IL-5+, IL-13+ ILC2 in the sputum 24 hours after allergen challenge, coincident with a decrease in blood ILC2. The investigators concluded that, although innate and adaptive immune cells are increased in the airways associated with allergic asthma, total and type 2 cytokine-positive ILC2 are increased only within the airways. Saglani et al..$^{50}$ reported IL-33, a potent activator of lung ILC2, as a factor that regulates airway remodeling in children with severe steroid-resistant asthma. In addition, we found that ILC2 in patients with asthma and upregulated expression of VEGF, which is a potent inducer of airway hyperresponsiveness. ${ }^{10}$ Whether inflammatory ILC2s are present in patients with asthma remains unknown and is a topic that warrants further investigation. ${ }^{11}$

There is emerging evidence that asthma may not simply be a Th2-dependent, IgE-mediated allergic inflammatory disease but that it also involves an innate pathway in which ILC2s provide a cellular source of IL-5 and IL-13, important for initiation of adaptive type 2 immune responses. ${ }^{51-53}$ Evidence for a role for ILC2s in driving type 2 immune responses comes from animal studies, with little information from patients with inflammatory disease and less so from patients with asthma. ${ }^{54,55}$ ILC2s, which are the earliest source of type 2 cytokines, mediate the initiation of eosinophilic inflammation in patients with asthma. ${ }^{56}$ Because there is evidence that Th2 cytokines are the product of Th2 cells, a number of treatments have been attempted that target Th2 cells and their cytokine, with modest response. ${ }^{57-63}$ It has been hypothesized that IL-5 and IL-13, Th2 cytokines, have been good therapeutic targets, are produced by ILC2s that are constitutively active deep inside mucosal surfaces. ${ }^{64}$ Therefore, agents that target ILC2, the source of these cytokines, deep in the mucosal tissues may prove more effective $\mathrm{e}^{55}$

Barnig et al. ${ }^{65}$ showed that, similarly to IL-25 and IL-33, prostaglandin D2 (PGD2) stimulated release of IL13 by CRTH2 ${ }^{+}$ILC2. Furthermore, the ILC2 as well as natural killer (NK) cells expressed receptor A lipoxin/formyl peptide receptor 2 (ALX/FPR2) receptors. The ligand for this receptor, lipoxin $\mathrm{A}_{4}$, stimulated an anti-inflammatory response by decreasing PGD2 and secretion of IL-13 by ILC2, which suggests a potential role of lipoxin A4 (LXA4) in treating asthma. ${ }^{65}$ Sugita et al. ${ }^{66}$ examined the role of ILC2 in regulating bronchial epithelial tight junction and barrier function in bronchial epithelial cells of patients with asthma, healthy human subjects, and ILC2 deficient mice. They found that when ILC2 was cultured with human bronchial epithelial cells, there was barrier dysfunction, which was represented by decreased transepithelial electrical resistance and increased epithelial permeability for large molecules across the epithelial layers in the experiment.

In subsequent experiments, this barrier dysfunction was reversed when IL-13 was neutralized in cultures of ILC2 and human bronchial epithelial cells. This indicated that ILC2 leads to bronchial epithelial barrier dysfunction through IL-13. Furthermore, in a murine model, IL-33 administration to wild-type mice and Rag2 ${ }^{-/-}$mice, which lack $\mathrm{T}$ and B cells, resulted in a disrupted tight junction; however, IL-33 administration to mice that lack ILC2 in addition to T and B cells, did not show any barrier dysfunction. Lastly, when mice were treated with IL-13, there was a significantly lower expression of tight junction mRNA. All together, these experiments revealed the role of ILC2 and IL-13 in bronchial epithelial barrier dysfunction. 
ILCs are classically divided into three subsets, ILC1, ILC2, and ILC3, based on their molecular and functional resemblance with effectors T cells. Forkhead Box P3 (FOXP3)-expressing ILCs that resemble regulatory $\mathrm{T}$ (Treg) cells have not been identified. Nevertheless, there was recent research of a similar subset that produces IL-10 and requires autocrine Transforming Growth Factor $\beta 1$ (TGFB1) for maintenance. ${ }^{67}$ These cells were termed regulatory ILC (ILCreg). ILCreg can inhibit innate intestinal inflammation. Whether ILCreg are involved in asthma and allergic disease, however, remains unknown. In addition, ILC2s possess substantial functional heterogeneity. A subset of ILC2 also produced IL-10, termed ILC2 $10 \cdot{ }^{68}$ Enhanced generation of $\mathrm{ILC}_{10}$ is associated with decreased eosinophil inflammation in mouse models, which indicates a regulatory function of ILC2 $2_{10}$. Function and regulation of these ILCregs in asthma and allergy warrants future investigation.

\section{ATOPIC DERMATITIS}

$\mathrm{AD}$ is a chronic pruritic inflammatory skin disease that occurs most frequently in children but that also affects adults. Fillagrin (FLG) is an important gene involved in skin barrier function. FLG mutation can lead to $\mathrm{AD}$, and studying this gene has helped our understanding of the pathogenesis of $\mathrm{AD}{ }^{69,70} \mathrm{Al}-$ though high levels of IL-13 and IL-4 are known to be expressed in AD lesions, little is known regarding how an inherited epidermal abnormality leads to impaired skin barrier and skin inflammation. ${ }^{14,71}$ The acute initiation of $\mathrm{AD}$ lesions is characterized by increased expression of Th2, Th22, and Th17 cytokines. Th2 and Th22 cytokines (IL-4, IL-13, IL-31, IL-22) seem to modulate the epidermal barrier function by suppressing the expression of terminal keratinocyte differentiation genes (e.g., FLG), which inhibits the production of antimicrobial peptides (AMPs) and promotes epidermal hyperplasia. ${ }^{71,72}$

The discovery of ILCs raises the question of their role in the involvement of AD. Maryam Salimi et al. ${ }^{73}$ examined peripheral blood and acute skin lesions of adults with AD for the presence of ILC2s to investigate whether ILC2 cells might contribute to the pathogenesis of AD. They found significantly more ILC2s in the skin biopsy specimens in the patients with $\mathrm{AD}$ than in healthy controls, but they found no difference in frequency of ILC2 in the peripheral blood of patients with AD compared with control patients. Kim et al. ${ }^{14}$ demonstrated that ILC2s accumulate in the lesional skin of patients with $\mathrm{AD}$ and that depletion of murine ILCs significantly ameliorates AD-like inflammation in their model, which supports the role of ILC2s in skin inflammation. Furthermore, they showed that ILC2 responses in the skin were dependent on TSLP. Targeting of TSLP in the future may provide a therapeutic option for a certain group of AD.

\section{FOOD ALLERGY}

Food allergies are common and affect up to $10 \%$ of the population, with an increasing prevalence over the past 2 to 3 decades, particularly in industrialized countries. ${ }^{74}$ Food allergy is thought to present secondary to a breakdown of immunologic and clinical tolerance to an ingested food, which results in IgE-mediated reactions or non-IgE-mediated disorders. This breakdown of tolerance leads to food allergen sensitization, which commonly occurs in the gastrointestinal tract and/or skin, presumably in conjunction with inflamed barrier function. ${ }^{75,76}$ Immune tolerance occurs in the gastrointestinal tract through the presentation of food antigen by $\mathrm{CD} 103^{+}$dendritic cells (DC), whereas, in the skin, tolerance develops through presentation of food antigen by $\mathrm{CD}_{11 \mathrm{~b}^{+}}$dermal DCs and Langerhans cells. ${ }^{77}$ DCs and Langerhans cells are antigen-presenting cells that induce Treg cells in the mesenteric and regional lymph nodes to promote tolerance. Induction of Treg cells is believed to be compromised in patients with food allergy and replaced by generation of unique antigen-specific Th2 cells that drive IgE class switching. ${ }^{78}$ Production of Th2 cytokines IL-4, IL-5, and IL-13 amplifies the allergic response by blocking induction of allergen-specific Treg cells and causes Th2 cell differentiation and IgE-driven mast cell activation. ${ }^{79,80}$

Although there are conflicting reports on the role of ILC2 in food allergen sensitization, numerous studies, mostly in murine models, seem to indicate that ILC2 plays a role in food allergy. ${ }^{81,82}$ In murine models, oral feeding of antigen plus adjuvant stimulates gut epithelial cells to express IL-33, which promotes the Th2 response. ${ }^{81}$ It has been reported that IL-33 promotes food allergy through expansion and activation of ILC2s, which then respond by producing large amounts of IL-4 and leads to suppression of Treg cells in the skin, lung, and small intestine. ${ }^{79}$ IL-33 also contributes to acute reactions to food by acting directly on mast cells and enhancing IgE-mediated activation. ${ }^{76}$ Noval Rivas et al. ${ }^{83}$ demonstrated that ILC2s play an important role in mediating oral sensitization to food allergens in a murine model, and, interestingly, mice prone to food allergy did not develop sensitization when ILC2 differentiation was compromised by concurrent IL-33R deficiency. The investigators report that ILC2s produce copious amounts of IL-4 sufficient to suppress allergen-specific induced-Treg (iTreg) cell differentiation during food allergy. ${ }^{83}$ Burton et al. ${ }^{84}$ reported intestinal ILC2 expansion in food allergy, driven by IgE-activated mast cells, which can enhance mast cell mediators of anaphylaxis production. 
Table 1 The relative frequency of inflammatory cells in known and projected subtypes of esophagitis

\begin{tabular}{|c|c|c|c|c|c|c|}
\hline & Controls & EoE & LyE & $\begin{array}{l}\text { High Cells, } \\
\text { Mixed }\end{array}$ & $\begin{array}{l}\text { Low Cells, } \\
\text { Mixed }\end{array}$ & $\begin{array}{l}\text { Group } 2 \text { ILC } \\
\text { Esophagitis+ }\end{array}$ \\
\hline Eosinophils & 0 & $* * * *$ & 0 & $* * *$ & $* *$ & $?$ \\
\hline Adaptive Lymphocytes & * & $* * *$ & $* * * *$ & $* * *$ & $* *$ & $?$ \\
\hline Group 2 ILC & * & $* *$ & $?$ & $?$ & $?$ & $?$ \\
\hline \multicolumn{7}{|c|}{$\begin{array}{l}\text { EoE = Eosinophilic esophagitis; LyE = lymphocytic esophagitis; ILC = innate lymphoid cell. }{ }^{*} \text { Relative presence of cells } \\
\left(0^{-* * *)} \text { extracted from data in } 3 \text { different studies. (References } 89,90,19\right) \\
* \text { Asterisks indicate the relative presence of cells extracted from three different studies. } \\
+ \text { Speculated phenotype. }\end{array}$} \\
\hline
\end{tabular}

\section{EOSINOPHILIC ESOPHAGITIS}

The medical history of EoE since its original description in 1978 was recently reviewed. ${ }^{85}$ Well recognized as a complex allergic disease by pediatric and adult medical specialists, its prevalence is increasing. ${ }^{86} \mathrm{~A}$ recent update summarized the histologic description of EoE, which includes the standard description of eosinophilic infiltration but also mentions increases in mast cells, B cells, and IgE-containing cells. ${ }^{87}$ T-cell infiltration in EoE has not been historically discussed in the context of EoE histopathology. A separate esophageal entity, lymphocytic esophagitis (LyE), now well described in the adult literature, was first described in $2006{ }^{88}$ It is histologically described as having peripapillary intraepithelial lymphocytes with few or no granulocytes.

In any normal esophageal biopsy specimen, lymphocytes are acceptably found and number $\leq 10 /$ hpf. $^{88}$ LyE is typically diagnosed with lymphocytes $\geq 20 / \mathrm{hpf}$ (variable among reports). ${ }^{88}$ Several recent studies seem to have expanded the concept of eosinophilic (granulocytic) and/or lymphocytic infiltration(s) in inflammatory esophagitis. The first report, published in 2017, presented the pathologic (histologic) pattern of eosinophilic and lymphocytic involvement in a collection of subjects $(N=311) .{ }^{89}$ The investigators, who also originally described LyE in 2006, used the T-cell marker CD3 coupled with the presence of granulocytic cells (hematoxylin and eosin stain) to classify their results. They divided their findings into four subgroups: EoE, LyE, compound EoE-LyE, and lymphocytic infiltration. The cell marker used to identify lymphocytes was CD3, and, because type 2 ILCs do not express CD3, the relative percentage of ILCs in their four phenotypes was not determined. Both adults and children were included, and children (ages $<20$ years) were identified in all four phenotypes.

In a second report, another medical center recently published their efforts to use cellular immunochemistry staining, coupled with flow cytometry, as a potential replacement of standard histologic assessment of EoE. ${ }^{90}$ Adaptive lymphocytes were present in both controls and subjects with active EoE, although intraepithelial lymphocytes were significantly higher in the subjects with active EoE. A third, collaborative project in the United States used subjects with active EoE and controls to compare the presence of ILC2s in esophageal biopsy specimens. ${ }^{19}$ ILC2s lack the markers for all other known immune cell lineages but express the chemoattractant homologous molecule seen on Th2 lymphocytes $\left(\mathrm{CD}_{4} 5^{+} \mathrm{Lin}^{-} \mathrm{CRTH} 2^{+}\right)$. Although controls demonstrated small numbers of adaptive lymphocytes with limited group 2 ILCs, subjects with active EoE had a significantly higher number of adaptive and innate lymphocytes (ILCs).

Finally, the collaborators who identified ILC2 in EoE expanded their findings in a preliminary report. ${ }^{91}$ They identified a key cytokine, IL-9, in regulating ILC2 biology and found that ILC2 from patients with active EoE upregulated IL-9R expression. ${ }^{91}$ We compiled information from recently published studies to construct a tabular review of inflammatory esophagitis (Table 1). The relative presence of the constitutively present or increased inflammatory cell population indicates the strength of the literature evidence for the cells (present in esophageal tissue) that might contribute to the pathology of different esophageal inflammatory subtypes. The increasing prevalence of EoE has mirrored the increase in all allergic diseases in the past 3 decades. ${ }^{85}$ Our understanding of the pathophysiology of EoE has made quantum leaps in a short period of time, with techniques learned from asthma and $\mathrm{AD}$ research. Analysis of the limited but current data strongly indicated a role for the ILC2 cell type in EoE, which mirrors findings in other allergic diseases. Furthermore, the role of ILCs in LyE, and, potentially, in other forms of inflammatory esophagitis, awaits additional study. The role of eosinophils and ILC in gastrointestinal inflammation was recently reviewed. ${ }^{92,93}$

\section{CONCLUSION}

Intensive work has been performed to reveal the function and regulation of ILC2s in allergic diseases, particularly AR and asthma, in recent years. Still, there 
is much more to investigate about this unique type of immune cell. What are the microanatomic locations of ILC2s in the upper and lower airways and in the skin? What other immune and nonhematopoietic cells directly and indirectly interact with tissue-resident ILC2s? Do ILC2s participate in forming specialized microanatomic structures that are yet to be characterized, and if so, how? What signals activate ILC2s in human allergic diseases, and how do such signals differ from those involved in T-cell activation? With the advance of new techniques and the increasing awareness of innate lymphocytes in health and disease, these and related questions, it is hoped, will be resolved in the very near future.

\section{ACKNOWLEDGMENTS}

We thank Marcia Lamb and Paul Fuestel for a manuscript review and helpful suggestions.

\section{REFERENCES}

1. Karta MR, Broide D, Doherty TA. Insights into group 2 innate lymphoid cells in human airway disease. Curr Allergy Asthma Rep. 2016; 16:8.

2. Moro K, Yamada $\mathrm{T}$, Tanabe $\mathrm{M}$, et al. Innate production of $\mathrm{T}(\mathrm{H}) 2$ cytokines by adipose tissue-associated c-Kit $(+) \mathrm{Sca}-1(+)$ lymphoid cells. Nature. 2010; 463:540-544.

3. Mjösberg JM, Trifari S, Crellin NK, et al. Human IL-25- and IL-33-responsive type 2 innate lymphoid cells are defined by expression of CRTH2 and CD161. Nat Immunol. 2011; 12:10551062.

4. Neill DR, Wong SH, Bellosi A, et al. Nuocytes represent a new innate effector leukocyte that mediates type- 2 immunity. Nature. 2010; 464:1367-1370.

5. Price AE, Liang HE, Sullivan BM, et al. Systemically dispersed innate IL-13-expressing cells in type 2 immunity. Proc Natl Acad Sci U S A. 2010; 107:11489-11494.

6. Mjösberg J, Bernink J, Golebski K, et al. The transcription factor GATA3 is essential for the function of human type 2 innate lymphoid cells. Immunity. 2012; 37:649-659.

7. Wilhelm C, Hirota K, Stieglitz B, et al. An IL-9 fate reporter demonstrates the induction of an innate IL-9 response in lung inflammation. Nat Immunol. 2011; 12:1071-1077.

8. Turner JE, Morrison PJ, Wilhelm C, et al. IL-9-mediated survival of type 2 innate lymphoid cells promotes damage control in helminth-induced lung inflammation. J Exp Med. 2013; 210: 2951-2965.

9. Pelly VS, Kannan Y, Coomes SM, et al. IL-4-producing ILC2s are required for the differentiation of $\mathrm{TH} 2$ cells following $\mathrm{He}$ ligmosomoides polygyrus infection. Mucosal Immunol. 2016; 9:1407-1417.

10. Shen X, Pasha MA, Hidde K, et al. Group 2 innate lymphoid cells promote airway hyperresponsiveness through production of VEGFA. J Allergy Clin Immunol. 2018; 141:1929-1931.e4.

11. Zhang $\mathrm{K}, \mathrm{Xu} \mathrm{X}$, Pasha MA, et al. Cutting edge: notch signaling promotes the plasticity of group-2 innate lymphoid cells. J Immunol. 2017; 198:1798-1803.

12. von Moltke J, O'Leary CE, Barrett NA, Kanaoka Y, Austen KF, Locksley RM. Leukotrienes provide an NFAT-dependent signal that synergizes with IL-33 to activate ILC2s. J Exp Med. 2017; 214:27-37.

13. Lund SJ, Portillo A, Cavagnero K, et al. Leukotriene C4 potentiates IL-33-induced group 2 innate lymphoid cell activation and lung inflammation. J Immunol. 2017; 199:1096-1104.
14. Kim BS, Siracusa MC, Saenz SA, et al. TSLP elicits IL-33-independent innate lymphoid cell responses to promote skin inflammation. Sci Transl Med. 2013; 5:170ra16.

15. Xue L, Salimi M, Panse I, et al. Prostaglandin D2 activates group 2 innate lymphoid cells through chemoattractant receptor-homologous molecule expressed on TH2 cells. J Allergy Clin Immunol. 2014; 133:1184-1194.

16. Yagi R, Zhong C, Northrup DL, et al. The transcription factor GATA3 is critical for the development of all IL-7R-expressing innate lymphoid cells. Immunity. 2014; 40:378-388.

17. Bartemes KR, Kephart GM, Fox SJ, Kita H. Enhanced innate type 2 immune response in peripheral blood from patients with asthma. J Allergy Clin Immunol. 2014; 134:671-678.e4.

18. Nagakumar P, Denney L, Fleming L, Bush A, Lloyd CM, Saglani S. Type 2 innate lymphoid cells in induced sputum from children with severe asthma. J Allergy Clin Immunol. 2016; 137:624-626.e6.

19. Doherty TA, Baum R, Newbury RO, et al. Group 2 innate lymphocytes (ILC2) are enriched in active eosinophilic esophagitis. J Allergy Clin Immunol. 2015; 136:792-794.e3.

20. Lao-Araya M, Steveling E, Scadding GW, Durham SR, Shamji $\mathrm{MH}$. Seasonal increases in peripheral innate lymphoid type 2 cells are inhibited by subcutaneous grass pollen immunotherapy. J Allergy Clin Immunol. 2014; 134:1193-1195.e4.

21. Borish L. Allergic rhinitis: systemic inflammation and implications for management. J Allergy Clin Immunol. 2003; 112:10211031.

22. Brożek JL, Bousquet J, Agache I, et al. Allergic Rhinitis and its Impact on Asthma (ARIA) guidelines-2016 revision. J Allergy Clin Immunol. 2017; 140:950-958.

23. Xu G, Zhang L, Wang DY, et al. Opposing roles of IL-17A and IL-25 in the regulation of TSLP production in human nasal epithelial cells. Allergy. 2010; 65:581-589.

24. Asaka D, Yoshikawa M, Nakayama T, Yoshimura T, Moriyama $\mathrm{H}$, Otori N. Elevated levels of interleukin-33 in the nasal secretions of patients with allergic rhinitis. Int Arch Allergy Immunol. 2012; 158(Suppl 1):47-50.

25. Haenuki Y, Matsushita K, Futatsugi-Yumikura S, et al. A critical role of IL-33 in experimental allergic rhinitis. J Allergy Clin Immunol. 2012; 130:184-194.e11.

26. Kamekura R, Kojima T, Takano K, Go M, Sawada N, Himi T. The role of IL-33 and its receptor ST2 in human nasal epithelium with allergic rhinitis. Clin Exp Allergy. 2012; 42:218-228.

27. Kamekura R, Kojima T, Koizumi J, et al. Thymic stromal lymphopoietin enhances tight-junction barrier function of human nasal epithelial cells. Cell Tissue Res. 2009; 338:283-293.

28. Zhu DD, Zhu XW, Jiang XD, Dong Z. Thymic stromal lymphopoietin expression is increased in nasal epithelial cells of patients with mugwort pollen sensitive-seasonal allergic rhinitis. Chin Med J (Engl). 2009; 122:2303-2307.

29. Mou Z, Xia J, Tan Y, et al. Overexpression of thymic stromal lymphopoietin in allergic rhinitis. Acta Otolaryngol. 2009; 129: 297-301.

30. Wang H, Mobini R, Fang Y, et al. Allergen challenge of peripheral blood mononuclear cells from patients with seasonal allergic rhinitis increases IL-17RB, which regulates basophil apoptosis and degranulation. Clin Exp Allergy. 2010; 40:1194-1202.

31. Matsumoto $Y$, Noguchi E, Imoto $Y$, et al. Upregulation of IL17RB during natural allergen exposure in patients with seasonal allergic rhinitis. Allergol Int. 2011; 60:87-92.

32. Ho J, Bailey M, Zaunders J, et al. Group 2 innate lymphoid cells (ILC2s) are increased in chronic rhinosinusitis with nasal polyps or eosinophilia. Clin Exp Allergy. 2015; 45:394-403.

33. Doherty TA, Scott D, Walford HH, et al. Allergen challenge in allergic rhinitis rapidly induces increased peripheral blood type 2 innate lymphoid cells that express CD84. J Allergy Clin Immunol. 2014; 133:1203-1205. 
34. Zhong H, Fan XL, Yu QN, et al. Increased innate type 2 immune response in house dust mite-allergic patients with allergic rhinitis. Clin Immunol. 2017; 183:293-299.

35. Fan D, Wang $X$, Wang $M$, et al. Allergen-dependent differences in ILC2s frequencies in patients with allergic rhinitis. Allergy Asthma Immunol Res. 2016; 8:216-222.

36. Mitthamsiri W, Pradubpongsa P, Sangasapaviliya A, Boonpiyathad T. Decreased CRTH2 expression and response to allergen re-stimulation on innate lymphoid cells in patients with allergen-specific immunotherapy. Allergy Asthma Immunol Res. 2018; 10:662-674.

37. Lombardi V, Beuraud C, Neukirch C, et al. Circulating innate lymphoid cells are differentially regulated in allergic and nonallergic subjects. J Allergy Clin Immunol. 2016; 138:305-308.

38. Kato Y, Akasaki S, Muto-Haenuki Y, Fujieda S, Matsushita K, Yoshimoto T. Nasal sensitization with ragweed pollen induces local-allergic-rhinitis-like symptoms in mice. PLoS One. 2014; 9:e103540.

39. Global Initiative For Asthma. (2017). Global Strategy for Asthma Management and Prevention. [online] Available at: http:/ / ginasthma.org/wp-content/uploads/2016/04/GINA2016-main-report_tracked.pdf [Accessed 7 Jan. 2017].

40. Kim HY, DeKruyff RH, Umetsu DT. The many paths to asthma: phenotype shaped by innate and adaptive immunity. Nat Immunol. 2010; 11:577-584.

41. Johnston RA, Zhu M, Rivera-Sanchez YM, et al. Allergic airway responses in obese mice. Am J Respir Crit Care Med. 2007; 176:650-658.

42. Kim EY, Battaile JT, Patel AC, et al. Persistent activation of an innate immune response translates respiratory viral infection into chronic lung disease. Nature Med. 2008; 14:633-640.

43. Pichavant M, Goya S, Meyer EH, et al. Ozone exposure in a mouse model induces airway hyperreactivity that requires the presence of natural killer T cells and IL-17. J Exp Med. 2008; 205:385-393.

44. Wright RJ. Stress and atopic disorders. J Allergy Clin Immunol. 2005; 116:1301-1306.

45. Allakhverdi Z, Comeau MR, Smith DE, et al. CD34+ hemopoietic progenitor cells are potent effectors of allergic inflammation. J Allergy Clin Immunol. 2009; 123:472-478.

46. Préfontaine D, Lajoie-Kadoch S, Foley S, et al. Increased expression of IL-33 in severe asthma: evidence of expression by airway smooth muscle cells. J Immunol. 2009; 183:5094-5103.

47. Christianson CA, Goplen NP, Zafar I, et al. Persistence of asthma requires multiple feedback circuits involving type 2 innate lymphoid cells and IL-33. J Allergy Clin Immunol. 2015; 136:59-68.e14.

48. Smith SG, Chen R, Kjarsgaard M, et al. Increased numbers of activated group 2 innate lymphoid cells in the airways of patients with severe asthma and persistent airway eosinophilia. J Allergy Clin Immunol. 2016; 137:75-86.e8.

49. Chen R, Smith SG, Salter B, et al. Allergen-induced increases in sputum levels of group 2 innate lymphoid cells in subjects with asthma. Am J Respir Crit Care Med. 2017; 196:700-712.

50. Saglani S, Lui S, Ullmann N, et al. IL-33 promotes airway remodeling in pediatric patients with severe steroid-resistant asthma. J Allergy Clin Immunol. 2013; 132:676-85.e13.

51. Bartemes KR, Iijima K, Kobayashi T, Kephart GM, McKenzie AN, Kita H. IL-33-responsive lineage- CD25+ CD44(hi) lymphoid cells mediate innate type 2 immunity and allergic inflammation in the lungs. J Immunol. 2012; 188:1503-1513.

52. Halim TY, Krauss RH, Sun AC, Takei F. Lung natural helper cells are a critical source of Th2 cell-type cytokines in protease allergen-induced airway inflammation. Immunity. 2012; 36: 451-463.

53. Walker JA, Barlow JL, McKenzie AN. Innate lymphoid cellshow did we miss them? Nat Rev Immunol. 2013; 13:75-87.
54. Barlow JL, McKenzie AN. Type-2 innate lymphoid cells in human allergic disease. Curr Opin Allergy Clin Immunol. 2014; 14:397-403.

55. Vercelli D, Gozdz J, von Mutius E. Innate lymphoid cells in asthma: when innate immunity comes in a Th2 flavor. Curr Opin Allergy Clin Immunol. 2014; 14:29-34.

56. Cosmi L, Annunziato F. Group 2 innate lymphoid cells are the earliest recruiters of eosinophils in lungs of patients with allergic asthma. Am J Respir Crit Care Med. 2017; 196:666-668.

57. Holgate ST. Pathophysiology of asthma: what has our current understanding taught us about new therapeutic approaches? J Allergy Clin Immunol. 2011; 128:495-505.

58. Liu Y, Zhang S, Li DW, Jiang SJ. Efficacy of anti-interleukin-5 therapy with mepolizumab in patients with asthma: a metaanalysis of randomized placebo-controlled trials. PLoS One. 2013; 8:e59872.

59. Castro M, Mathur S, Hargreave F, et al. Reslizumab for poorly controlled, eosinophilic asthma: a randomized, placebo-controlled study. Am J Respir Crit Care Med. 2011; 184:1125-1132.

60. Corren J, Lemanske RF, Hanania NA, et al. Lebrikizumab treatment in adults with asthma. N Engl J Med. 2011; 365:1088-1098.

61. Gauvreau GM, Boulet LP, Cockcroft DW, et al. Effects of interleukin-13 blockade on allergen-induced airway responses in mild atopic asthma. Am J Respir Crit Care Med. 2011; 183:10071014.

62. Noonan M, Korenblat P, Mosesova S, et al. Dose-ranging study of lebrikizumab in asthmatic patients not receiving inhaled steroids. J Allergy Clin Immunol. 2013; 132:567-574.e12.

63. Wenzel S, Ford L, Pearlman D, et al. Dupilumab in persistent asthma with elevated eosinophil levels. N Engl J Med. 2013; 368:2455-2466.

64. Nussbaum JC, Van Dyken SJ, von Moltke J, et al. Type 2 innate lymphoid cells control eosinophil homeostasis. Nature. 2013; 502:245-248.

65. Barnig C, Cernadas M, Dutile S, et al. Lipoxin A4 regulates natural killer cell and type 2 innate lymphoid cell activation in asthma. Sci Transl Med. 2013; 5:174ra26.

66. Sugita K, Steer CA, Martinez-Gonzalez I, et al. Type 2 innate lymphoid cells disrupt bronchial epithelial barrier integrity by targeting tight junctions through IL-13 in asthmatic patients. J Allergy Clin Immunol. 2018; 141:300-310.e11.

67. Wang S, Xia P, Chen Y, et al. Regulatory innate lymphoid cells control innate intestinal inflammation. Cell. 2017; 171:201216.e18.

68. Seehus CR, Kadavallore A, Torre B, et al. Alternative activation generates IL-10 producing type 2 innate lymphoid cells. Nat Commun. 2017; 8:1900.

69. Palmer $\mathrm{CN}$, Irvine AD, Terron-Kwiatkowski A, et al. Common loss-of-function variants of the epidermal barrier protein filaggrin are a major predisposing factor for atopic dermatitis. Nature Genetics. 2006; 38:441-446.

70. Sandilands A, Sutherland C, Irvine AD, McLean WH. Filaggrin in the frontline: role in skin barrier function and disease. J Cell Sci. 2009; 122:1285-1294.

71. Leung DY, Boguniewicz M, Howell MD, Nomura I, Hamid QA. New insights into atopic dermatitis. J Clin Invest. 2004; 113:651657.

72. Leung DY, Guttman-Yassky E. Deciphering the complexities of atopic dermatitis: shifting paradigms in treatment approaches. J Allergy Clin Immunol. 2014; 134:769-779.

73. Salimi M, Barlow JL, Saunders SP, et al. A role for IL-25 and IL-33-driven type-2 innate lymphoid cells in atopic dermatitis. J Exp Med. 2013; 210:2939-2950.

74. Osborne NJ, Koplin JJ, Martin PE, et al. Prevalence of challengeproven IgE-mediated food allergy using population-based sampling and predetermined challenge criteria in infants. J Allergy Clin Immunol. 2011; 127:668-676.e1-2. 
75. Brough HA, Liu AH, Sicherer S, et al. Atopic dermatitis increases the effect of exposure to peanut antigen in dust on peanut sensitization and likely peanut allergy. J Allergy Clin Immunol. 2015; 135:164-170.

76. Galand C, Leyva-Castillo JM, Yoon J, et al. IL-33 promotes food anaphylaxis in epicutaneously sensitized mice by targeting mast cells. J Allergy Clin Immunol. 2016; 138:1356-1366.

77. Tordesillas L, Berin MC, Sampson HA. Immunology of Food Allergy. Immunity. 2017; 47:32-50.

78. Wambre E, Bajzik V, DeLong JH, et al. A phenotypically and functionally distinct human $\mathrm{T}_{\mathrm{H}} 2$ cell subpopulation is associated with allergic disorders. Sci Transl Med. 2017; 9. pii: eaam9171.

79. Noval Rivas M, Burton OT, Wise P, et al. Regulatory T cell reprogramming toward a Th2-cell-like lineage impairs oral tolerance and promotes food allergy. Immunity. 2015; 42:512-523.

80. Burton OT, Noval Rivas M, Zhou JS, et al. Immunoglobulin E signal inhibition during allergen ingestion leads to reversal of established food allergy and induction of regulatory $\mathrm{T}$ cells. Immunity. 2014; 41:141-151.

81. Chu DK, Llop-Guevara A, Walker TD, et al. IL-33, but not thymic stromal lymphopoietin or IL-25, is central to mite and peanut allergic sensitization. J Allergy Clin Immunol. 2013; 131:187-200.e1-8.

82. Lee JB, Chen CY, Liu B, et al. IL-25 and CD4(+) TH2 cells enhance type 2 innate lymphoid cell-derived IL-13 production, which promotes IgE-mediated experimental food allergy. J Allergy Clin Immunol. 2016; 137:1216-1225.e5.

83. Noval Rivas M, Burton OT, Oettgen HC, Chatila T. IL-4 production by group 2 innate lymphoid cells promotes food allergy by blocking regulatory T-cell function. J Allergy Clin Immunol. 2016; 138:801-811.e9.
84. Burton OT, Medina Tamayo J, Stranks AJ, et al. IgE promotes type 2 innate lymphoid cells in murine food allergy. Clin Exp Allergy. 2018; 48:288-296.

85. Hopp RJ. Eosinophilic oesophagitis. From rare to commonplace. What are the potential explanations? EMJ Gastroenterol. 2016; 5:89-95.

86. Dellon ES. Epidemiology of eosinophilic esophagitis. Gastroenterol Clin North Am. 2014; 43:201-218.

87. Bonis PA, Furuta GT. Clinical manifestations and diagnosis of eosinophilic esophagitis. UpToDate. 2016; 2010. https:/ /www.uptodate.com/contents/clinical-manifestations-and-diagnosisof-eosinophilic-esophagitis.

88. Rubio CA, Sjödahl K, Lagergren J. Lymphocytic esophagitis: a histologic subset of chronic esophagitis. Am J Clin Pathol. 2006; 125:432-437.

89. Rubio CA, Ichiya T, Schmidt PT. Lymphocytic oesophagitis, eosinophilic oesophagitis and compound lymphocytic-eosinophilic oesophagitis I: histological and immunohistochemical findings. J Clin Pathol. 2017; 70:208-216.

90. Wen T, Kuhl J, Putnam P, et al. A flow cytometry-based diagnosis of eosinophilic esophagitis. J Allergy Clin Immunol. 2017; 140:1736-1739.e3.

91. Doshi A, Baum R, Holanda P, et al. Group 2 innate lymphoid cells and IL-9 receptor are increased in active eosinophilic esophagitis. J Allergy Clin Immunol. 2016; 137; Suppl: AB279.

92. Morita H, Moro K, Koyasu S. Innate lymphoid cells in allergic and nonallergic inflammation. J Allergy Clin Immunol. 2016; 138:1253-1264.

93. O'Sullivan JA, Bochner BS. Eosinophils and eosinophil-associated diseases: an update. J Allergy Clin Immunol. 2018; 141: 505-517. 